\title{
Assessment of the Performance of School Management Committees (SMCs) Towards the Attainment of Quality Basic Education in the Tarkwa-Nsuaem Municipality of Ghana
}

\author{
Theophilus Andoh-Robertson ${ }^{1 *} \quad$ Samuel Effah $^{2} \quad$ Thomas Bright Eshun $^{3} \quad$ Miss Angelina Kwasi $^{4}$ \\ 1.Head, Guidance and Counselling Unit, University of Mines and Technology (UMaT), P. O. Box 237, Tarkwa, \\ Ghana \\ 2.Head, Audit Unit, University of Mines and Technology (UMaT), P. O. Box 237, Tarkwa, Ghana \\ 3.Snr. Assistant Registrar, University of Mines and Technology (UMaT), P. O. Box 237, Tarkwa, Ghana \\ 4.Headmistress, UMaT Basic School, University of Mines and Technology (UMaT), P. O. Box 237, Tarkwa, \\ Ghana
}

\begin{abstract}
The study sought to assess the performance of School Management Committees (SMCs) towards the attainment of Quality Basic Education in the Tarkwa-Nsuaem Municipality through the views of education officials, head teachers, teachers and SMC Members. A descriptive survey design was adopted for the study. A stratified sampling and simple random sampling techniques were adopted to select a sample size of two hundred and thirty (230) respondents. Questionnaire and interview guides were used to collect data from the respondents, validated by the researchers and analyzed by the use of descriptive statistics. The findings indicated that SMCs' had good performance on almost all performance indicators, however, were not doing enough to ensure financial accountability in schools. Also there was weak statistical correlation between SMCs performance and academic performance in the Municipality. Finally, it was recommended that SMCs should be given the needed support including regular training, especially, on financial accountability. Also much effort is needed to be done by SMCs in the Tarkwa-Nsuaem Municipality (TNM) to ensure quality basic education. Conclusively, the good performance of SMCs is therefore one of the major sureties to attaining quality basic education in Tarkwa Nsuaem Municipality. It is hoped that the findings will serve as tools for change of practice of supervision of all stakeholders in the delivery of quality basic education in public basic schools.
\end{abstract}

Keywords: Quality Basic Education, Assessment, Performance. School Management Committee, SchoolCommunity, FCUBE, School Budget Hearing.

DOI: $10.7176 /$ RHSS/10-16-03

Publication date:August $31^{\text {st }} 2020$

\section{Introduction}

\subsection{Background to the Study}

The importance of education has never been doubted or contradicted in any part of the world. It is treasured in society because it provides the tool for imparting knowledge and skills. It cultivates values, morals, character and develops the intellect. Strategies and methods required in imparting knowledge are many and varied. One of such strategies was the coordinated effort provided through the partnership activities of the community and the School Management Committees (SMCs). The activities of SMCs are critical at the basic school level where teachers and school management have to cope with young children and adolescents in the development of their intellect and personality. The SMCs play critical roles in enforcing standards, developing and maintaining school infrastructure, and creating a partnership between teachers, pupils and district authorities to bring about needed changes (Ghana Education Service [GES], 2001).

According to Akyeampong (2005), after the new structure of Education Reform had been put in place in 1987, government introduced an education sector policy in 1996 known as "Free Compulsory Universal Basic Education (FCUBE) in line with Article 25 of the 1992 constitution of the Republic of Ghana. FCUBE represented the effort to ensure that all children of school-going-age received free and compulsory 'quality' primary education by 2005 . The new policy helped to create a motivation for a coordinated sector programme providing a framework for donor support to education, and a drive for educational decentralization with greater recognition of the important role of community participation in school management for school improvement. FCUBE was developed on the basis of three cost components:

i. Improving quality of teaching and learning through the review and revision of teaching materials, new measures on teacher incentives, and a focus on in-service teacher training.

ii. Strengthening management at both central and district levels; and

iii. Improving access and participation especially through schemes that encouraged girls' participation at primary level.

Ironically, there has not been a commensurate improvement in quality teaching and learning at the basic 
schools. Increased funding has not in any way contributed to improvement in quality in terms of literacy and cognitive abilities of the basic pupils (Owolabi, 1999). Owolabi further observed that the present level of quality basic education in many schools is insufficient to impart sustainable literacy and knowledge, skills and habits required for full social and economic participation in society. To stem the tide of low quality teaching and learning which often results in low school performance, School Management Committee has been identified as a strategic intervention towards improvement in school performance (Opare, 1999).

It is worthy of note, that the issue of educational management is not a contemporary one in Ghana. In this regard, various initiatives and interventions have been made so that the basic school pupil who is the focus of all educational policies really benefit. It is for this reason that the community which has immediate contact with the child is ever called upon to assist in school management; hence, the establishment of School Management Committees (SMCs) for schools by an Act of parliament in 1994 alongside the introduction of FCUBE policy in Ghana.

\subsection{Statement of the Problem}

Various educational reviews and reforms and the desire of the community to be involved in school management culminated in the introduction of systems, interventions and structures from the Municipal Education Office to the school community. Most of these strategies were to ensure effective school management that will yield high accountability and improvement in quality education delivery in the country. Amongst them is the School Management Committee (SMC).

The SMC is a Committee designated under the Ghana Education Service Act of 1994. It is a school community-based organization aimed at strengthening community participation as a means of facilitating quality education delivery (Osei-Owusu and Sam, 2012). The SMC is a representation of the entire school community of a particular school or cluster of schools. The school community therefore becomes its constituency. Azeem (2010) on school management systems in Ghana showed that school governance was generally weak. For instance, few parents and SMC/PTA members involved themselves in school financial management, though the opportunities for participation existed. SMCs lacked knowledge of financial issues.

Inferring from the expected roles of SMCs, one would want to see a vibrant SMC in school communities collaborating the activities and efforts of the basic school head. It is worthy of note that the performance of the SMCs in most public basic schools in Tarkwa-Nsuaem-Municipality (TNM) have not been assessed to determine its effectiveness. It is for these reasons that the researchers sought to assess how SMCs have performed vis-à-vis their objectives and also the challenges that confront them in the Municipality.

\subsection{Purpose of the Study}

The main aim of the study was to examine the performance of SMCs in public basic schools in the TarkwaNsuaem Municipality. The study sought to analyse the role of SMCs towards quality basic education in the public basic schools in TNM.

\subsection{Research Questions}

The study was guided by the following research questions:

i. What is the level of performance of SMCs in achieving quality basic education in TNM

ii. What is the relation between SMC performance and academic performance (quality basic education) in TNM?

iii. What are the challenges of SMCs in the Tarkwa-Nsuaem Municipality?

\subsection{Significance of the Study}

The study is beneficial, not only to the schools but also has the strength of contributing a wealth of information to existing literature on school management in basic schools. The study will draw attention and serve as a reminder to the school heads and other stakeholders, of the critical important roles of the SMC and the need to resource them. It is hoped that the findings will serve as tools for change of practice of supervision of all stakeholders in the quality of basic education in public basic schools.

Furthermore, the findings would galvanize schools whose SMCs are dormant and thus influence their modus operandi in the schools-communities. It is believed that this will help shape and inform stakeholders' perception about SMC. The findings of the study will bring the attention of head teachers, GES and the government to appreciate the role of SMCs in school management and this will initiate national debate and revive the wheel for effective monitoring of the activities of the SMCs in schools.

\subsection{Delimitation of the Study}

The study was restricted to only the performance of School Management Committees in public basic schools so that in-depth analysis could be carried out. Geographically, it was delimited to only public basic schools in the 
Tarkwa-Nsuaem Municipality.

\subsection{Definition of Terms}

Effectiveness: It is the extent to which the set goals or objectives of a school programme are accomplished.

Assessment: involves the measurement of performance against a set of criteria.

School Management Committee (SMC): it is a representation of the entire school community of a particular school or cluster of schools.

School Community: made up of the political/ traditional leadership of an area, PTA/SMCs, Town Development Committees, Non-Governmental Organizations, the religious bodies and the residents in that area.

School Budget Hearing: A platform that allows various stakeholders to make inputs to the school budgets and find possible ways of funding it.

\section{Review of Related Literature}

Conceptually, the framework for this study sought to look at the established indicators of school management performance that influenced the delivery of quality basic education. In this regard, the attitudes of both the basic school heads and SMC members were brought into sharp focus, how SMCs operated in the schools, the form of school related supports that SMCs should enjoy and the kind of school environment SMCs need to operate from were very crucial in quality education delivery.

\section{Methodology}

The study sought to analyze the operations of School Management Committees (SMC) in the Tarkwa-Nsuaem Municipality. This chapter dealt with the procedures employed to undertake the study. It specifically outlines the research design, the population, sample and sampling procedures, the research instruments, data collection procedures data analysis plan and profile of the study area.

\subsection{Research Design}

A research design can be seen as the vehicle that enables the researchers to be transported from a state of ignorance to a state of knowledge. The study was both qualitative and quantitative by nature. It was located within the descriptive survey design. The researchers used the descriptive research design because it is flexible and allowed the researchers to discover new issues related to the study. The study design was also a combination method that permitted the use of both quantitative and qualitative techniques to gather and analyse data. The appropriateness of the study design lied in the fact that it was concerned with the present status of a phenomenon and purports to give accurate description of activities, objects, or process and persons; the nature of prevailing conditions, practices, attitudes and trend that are developed (Amedahe \& Asamoah- Gyimah, 2005).

The purpose of the design was to observe, describe and document aspects of a situation as it naturally occurred. For this study, since the conditions or events either existed already or have occurred (i.e. how the SMCs have operated since their inception), the researchers selected relevant variables for analysis of their relationships. This was done taking cognisance of the objective of the study.

\subsection{Population}

The population for the study was all SMCs and five (5) Senior Education Officers in the Tarkwa-Nsuaem Municipality. The Municipality has been zoned into eight (8) different educational circuits. These are Tarkwa, Nsuaem North and South, Benso, Fiase, Akyeampim, Nsuta, and Dompim Circuits. The Municipality also has over 120 fully functional public basic schools with 85 SMCs. Each SMC is made up of 9 members. Hence, the total population for the study was 770 .

\subsection{Sample and Sampling Procedure}

In all, 25 SMCs were sampled in addition to five (5) Municipal Education Officers and this yielded a total sample size of One Hundred and Thirty (230) respondents. Consequently, proportional stratified sampling and purposive sampling methods were used to select respondents for the study. Stratified sampling method allowed grouping the population according to certain characteristics that contributed to the representativeness of the sample. For instance, it guided in selecting SMCs from each of the eight (8) circuits; urban/rural community schools. After the stratification, a simple random sampling technique helped to select the required percentage of the population from each stratum (circuit) to form the sample.

The lottery method, a type of simple random technique was employed to select individual SMCs from the various strata. As a result, SMCs selected were; 4 from Tarkwa and 3 each from Nsuaem North and South; Benso, Fiase, Akyeampim; Nsuta, and Dompim Circuits respectively. It is important to stress that the method ensured that each SMC stood the chance of being selected. According to Amedahe and Asamoah-Gyimah (2005), the technique is appropriate to use when the population of study is similar in characteristics of interest. Sampling 
technique ensured that respondents from each public basic school stood an equal and independent opportunity of being selected.

\subsection{Instruments}

In collecting data for the study, the researchers employed the use of questionnaires, structured interview guides and observation checklists. These instruments were stable, consistent and a uniform measure, without variation and can be completed at the respondent's convenience (Amedahe \& Asamoah-Gyimah, 2005). The population for the study was largely literates (Teachers, GES Officials) hence, questionnaires were therefore convenient to use.

The instruments were in three categories, i.e. A, B and C. Category 'A' contained questionnaires for Education Officers, heads and teachers that require information on the operations of SMC towards quality basic education in Tarkwa-Nsuaem Municipality. This contained both close-ended and open-ended questions for respondents which sought their views on School Management and their role to ensure school effectiveness. The instruments were developed and modified into Likert's four-point response rating scale ranging from Strongly Agree (4 points), Agree (3 points), Disagree (2 points) and Strongly Disagree (1 point). This was for the purposes of ensuring that every respondent expressed an opinion about the issues being raised. Category $\mathrm{B}$ and $\mathrm{C}$ were an observational checklist and the interview guides for SMC based on the topic under study. The interviews sought the opinions of these personnel on the operations of SMCs towards quality education in Tarkwa-Nsuaem Muinicipality.

\subsection{Validity and Reliability of the Instruments (Pilot Testing)}

To test the reliability and validity of the research instruments, pilot- testing was conducted in the University of Mines and Technology Basic School (UBaS), a privately owned basic school in the Tarkwa-Nsuaem Education Directorate of the Western Region. The choice of UBaS for the pilot testing was because it had so much commonality with the chosen area schools. The pilot test unearthed the flaws, in terms of wording, poor choices and ambiguities in the instruments. This promoted the reliability and validity of the instruments.

A correlation coefficient using the Cronbach's coefficient was computed to ascertain the reliability of the instruments. The Cronbach's alpha values obtained were .71 for Appendix A, Education Officials questionnaires and .70 for Appendix B, interview guide for SMC members; an indication of a high reliability of the instruments.

\subsection{Data Collection Procedure}

The researchers personally administered the questionnaires and the interview guides to the respondents and again collected the completed items. This was done after the researchers had presented a letter of introduction from the district education office to the visiting schools. This exercise was done within a period of 5 weeks in 2020. For the interviews, prior appointments were booked with the respondents and each one of them was interviewed at the appointed date and time. In all, 160 questionnaires and 70 interview guides were administered. This resulted in the high return rate of the instruments. The researchers were able to retrieve $88.5 \%$ of completed questionnaires and interview guides.

\subsection{Data Analysis Procedure}

Analysis of the data entailed both quantitative and qualitative techniques. Patton (as cited in Inkoom, 2003) observed that qualitative analysis transforms data into findings without any formula. The Likert four-point response rating scale was scored in this order: Strongly Agree (4 points), Agree (3 points), Disagree (2 points) and Strongly Disagree (1). Discretion can be offered but the final determination remains unique for each researcher. Quantitative data were analyzed using appropriate test statistics such as frequencies and the Pearson Product Moment Correlation on relationships and associations. There was also a descriptive analysis of the essential component of most of the data to determine the relationship between variables. The interview data was analysed using percentages, means and Pearson product Moment Correlation. The findings were summarized according to the variables being measured and presented in a form that makes easy understanding. Fairness was the hallmark in interpreting and communicating the findings which was based on majority views, nature of research questions and purpose of the study.

\subsection{Profile of the Study Area}

The Tarkwa Nsuaem Municipality as one of the Districts in the Western Region of Ghana is located between Latitude 400' $\mathrm{N}$ and $50040^{\prime} \mathrm{N}$ and Longitudes $1045^{\prime} \mathrm{W}$ and $2010^{\prime} \mathrm{W}$. It is bounded to the north by the Wassa Amenfi East District, to the south by the Ahanta West District, to the West by the Nzema East Municipal and to the East by Mpohor Wassa East. The municipality has a total land area of $2354 \mathrm{~km}$. The district is one of the richest in Ghana in terms of natural resources. Like, Obuasi in the Ashanti Region of Ghana, gold is its major natural resource. There is also a Manganese Mine at Nsuta a suburb of Tarkwa. The Aboso Glass Factory, which 
was set up by Ghana's first President, Osagyefo Dr. Kwame Nkrumah, though now defunct is also in the Municipality. The Tarkwa Gold Mine is situated some four kilometers west of the town of Tarkwa. The district also has the Region's only public university - the University of Mines and Technology, Tarkwa.

According to the Ghana 2010 population and housing census, Tarkwa Nsuaem Municipality recorded a population of 90,477 representing 3.8 percent of the Western regional population. The sex distribution of the population indicates that there are more males $(51.6 \%)$ than females $(48.4 \%)$. The municipality is predominantly rural with $69.7 \%$ of its population residing in the rural areas (Ghana population and housing census, 2010).

\section{Results and Discussion}

The major task of the study was to examine the performance of SMCs towards quality basic education in the Tarkwa-Nsuaem Municipality. In pursuance of that, research instruments developed were to seek answers to research questions and test some of the findings emerged from the review of related literature.

\subsection{Demographic Characteristics of Respondents}

The tables and figures below provide the characteristics of respondents involved in the study. These characteristics include gender, age and occupations of respondents.

\subsubsection{Gender of Respondents}

Table 1 presents the data on the gender of respondents involved in the study. The data shows that $73 \%(168)$ of the respondents were males while $27 \%$ (62) were females.

Table 1: Distribution of Gender of Respondents

\begin{tabular}{lrr}
\hline Gender & $\mathrm{N}$ & $\%$ \\
\hline Male & 168 & 73.0 \\
Female & 62 & 27.0 \\
\hline Total & $\mathbf{2 3 0}$ & $\mathbf{1 0 0 . 0}$ \\
\hline 4.1 .2 & Occupation of Respondents &
\end{tabular}

An analysis of members' occupations is presented in Table 2.

Table 2: Frequency Distribution of Members' Occupation

\begin{tabular}{lcc}
\hline Occupation & $\mathrm{N}$ & $\%$ \\
\hline Farming & 54 & 23.5 \\
Teaching & 60 & 26.1 \\
Mining & 86 & 37.4 \\
Other(specify) & 30 & 13.0 \\
\hline Total & $\mathbf{2 3 0}$ & $\mathbf{1 0 0 . 0}$ \\
\hline
\end{tabular}

The results from Table 2 indicate that $23.5 \%$ and $26.1 \%$. of members were farmers and teachers respectively.Mining 37.4\% was the predominant occupation engaged by majority of SMC members. However, the danger here is that, the high percentage of local miners on the SMC board, who were deemed not to have enough time, might have participated very little during meetings and referred strong issues to more few groups such as the teachers and farmers.

\subsection{Performance Indicators of SMC}

Research question 1 sought to establish the level of performance of SMCs in the Tarkwa-Nsuaem Municipality. Table 3 presents the data collected.

Table 3: Distribution of Performance Indicators of School Management Committees

\begin{tabular}{lllllll}
\hline Performance & SA \% & A \% & D \% & SD \% & M & Std. \\
\hline Organization/attendance of Executive meeting & 16.5 & 26.5 & 20.0 & 37.0 & 2.23 & 1.12 \\
Organization/attendance of General meeting & 40.0 & 49.6 & 10.0 & 0.4 & 3.29 & 0.66 \\
Visit to School & 33.5 & 34.3 & 23.9 & 8.3 & 2.93 & 0.95 \\
Monitor pupil/teacher attendance & 40.0 & 22.2 & 29.1 & 8.7 & 2.93 & 1.02 \\
Teacher Accommodation & 21.3 & 17.0 & 30.4 & 31.3 & 2.28 & 1.12 \\
Monitor Capitation grant & 13.1 & 26.5 & 39.1 & 21.3 & 2.31 & 0.95 \\
Settle disputes among Teachers & 47.8 & 30.4 & 15.7 & 6.1 & 3.20 & 0.92 \\
Do minor repairs & 48.7 & 22.2 & 8.7 & 20.4 & 3.11 & 1.07 \\
Enrolment Drive \& Retention & 26.1 & 51.7 & 13.9 & 8.3 & 2.96 & 0.86 \\
Ensures Accountability & 20.0 & 19.5 & 25.7 & 34.8 & 2.25 & 1.14 \\
\hline
\end{tabular}

Note: $\mathrm{N}=230, \quad \mathrm{SA}=$ Strongly Agree, $\mathrm{A}=$ Agree, $\mathrm{D}=$ Disagree, $\mathrm{SD}=$ Strongly Disagree

\subsubsection{SMC Executive Meeting}

From Table 3, majority (57.0\%) of SMCs did not organize and attend executive meetings. The average assessment indicates the performance was low $(\mathrm{M}=2.23)$. This means members denied themselves the time to 
meet as executives to deliberate on issues before taking them to general forum. The irregular attendance at executive meetings also affected some members in their involvement in the implementation of programmes and projects. This could have led to abandonment of programmes and projects earmarked. They failed to comply with the directives that they should attend executive meetings at least once a term (GES, 2001).

\subsubsection{SMC General Meeting}

Again, from Table 3, 89.6\% of the respondents said SMCs organized general meetings where parents and other stakeholders were involved. At such meetings, issues affecting schools such as teaching and learning, school discipline, school attendance, infrastructure and school performance might have been discussed. From the sample, the average performance was $(\mathrm{M}=3.29)$, which indicates good performance. The level of performance was therefore high. This result conforms to GES (2001) directive that SMCs should organize general meetings at least once a term where school policies are discussed. If the people were informed about policies, programmes and projects, they would be empowered to monitor their implementation at the local level and make meaningful contributions.

\subsubsection{Visit to Schools by SMC}

From Table 3,67.8\% of SMC members paid regular visit to schools as part of their routine activities. As they visited the schools they were made to sign the Visitors' Book. These visits perhaps afforded members the chance to inspect school premises to be sure that teaching and learning took place in a safe and conducive atmosphere. Such visits also could have allowed them to identify school infrastructural needs and where there was the need for immediate repairs. The performance of the sample in terms of school visits was relatively high $(M=2.93, S D$ $=0.95)$. The figures indicate a high performance by the sampled SMC members. The practice is in conformity to GES (2001) directive that members should ensure that the premises of the school are in good sanitary and structurally safe conditions.

\subsubsection{Monitoring Pupil/Teacher Attendance}

From Table 3,62.2\% of the respondents monitored school attendance. The average performance of SMC with respect to monitoring pupils and teacher attendance was 2.93. The result indicates the sample agreed that SMC monitored school attendance as spelt out by Attakpa \& Ankomah, (1998); GES, (2001), that SMC should monitor school attendance to ensure that school contact hours were being used effectively.

\subsubsection{Teachers' Accommodation}

From Table 3, SMCs' involvement in assisting newly posted teachers to secure residential accommodation was found to be very low (38.3\%). The average performance was 2.28 which fell below expectation. The figure indicates a low performance. The result clearly contravenes and contradicts Buah-Bassuah (2004); GES (2001) that SMCs should assist in securing accommodation for teachers especially newly posted ones.

\subsubsection{Monitoring Capitation Grant}

From Table 3, only few (39.6\%) of the respondents said that they were involved in the monitoring of the capitation grant. The sample as a whole indicated that the relative performance of SMCs in monitoring capitation grant was low $(\mathrm{M}=2.31)$. Several reasons might have accounted for this including lack of openness on the part of some heads of schools, members poor knowledge in school finance. It became clear that most of the schools did not inform SMC members how the grants were disbursed. This practice portrays weakness in school governance and thus confirms Azeem (2010) that school governance was generally weak and that some SMCs did not know that they had the right to enquire about school finance and failed to stop resource leakages.

\subsubsection{Settlement of Disputes among Teachers}

From Table 3, 78.2\% of respondents said SMC members involved in disputes and conflicts settlement in the schools whilst referring other serious disciplinary matters to the District Director of Education for action. These mainly involved teachers, pupils and some members of the community. The average performance of the SMC was $3.2(\mathrm{SD}=0.92)$, which indicates a high performance. The result corroborates and is in pursuance of their role in school management noted by Buah-Bassuah, (2004) and GES, (2001) that SMCs assisted heads in resolving school conflicts. These conflicts occurred between pupils and teachers, between teachers and between teachers and community members. The readiness of the conflict resolution moves by the SMCs helped the heads in their management functions. These initiatives improved school-community relation.

\subsubsection{Minor Repairs done by SMC}

From Table 3,70.9\% of respondents said SMCs did carry out school minor repairs like repairs of windows, doors broken furniture, replacements of school roofing sheets and other renovations works such as painting. The average performance by the sample was 3.11. The value indicates appreciable performance.

\subsubsection{SMCs' Role in Enrolment Drive \& Retention}

From Table 3,77.8\% of SMC members were involved in school enrolment drive and retention. The average performance was 2.96. This means majority of SMC members had taken the issues of providing quality basic education as a major duty and commitment owed the schools in their jurisdiction. They organized community forum to whip parents and community members' interest in education. SMC members used reward of regular pupils to ensure that pupils were retained in school. This finding validates Buah-Bassuah, (2004); Mensah, (2003) 
\& GES, (2001) that SMCs had involved themselves in activities that were aimed at increasing access and participation.

\subsubsection{SMCs' Role in Ensuring School Accountability}

From Table 3, 60.5\% of the SMC members failed to assist in ensuring school accountability. The average assessment was 2.25 . The value indicates a weak performance. The many reasons adduced for this situation were that, it was not within their purview and that enquiring into such issues often raised tension between them and the school authorities. Others too, said that some of the heads did not engage them in school financial issues. The finding shows that SMCs failed to perform their role to serve as checks and balances on the school administration to stop leakages in resource flow as they occurred. This result contradicts Mensah, (2003); Obeng-Darko, (2005) that SMC were to maintain proper books of accounts and provide financial information required by management to control the effective implementation of the school grants, but corroborates Azeem (2010) that few parents, SMC or PTA members involved themselves in school financial management, though the opportunities for their participation existed. The poor knowledge of finances reduces public access to school financial information.

\subsection{Relationship between SMCs' Performance and School Academic Performance}

Research question 2 sought to find the relationship between SMC's performance and school academic performance. As a result, the Pearson's Product -Moment Correlation Coefficient was computed to assess whether there was a relationship between the performance of SMCs and school academic performance. The result is presented in Table 4.

Table 4: Distribution of Relationship between Schools' Performance and

\begin{tabular}{ccc} 
Table 4: Distribution of Relationship between Schools' Performance and & SMCs' P \\
\hline Average School Performance & \multicolumn{3}{c}{ Average SMC Performance } \\
\hline (Pearson) average school Performance & 1.000 & .100 \\
Sig. (2-tailed) & 230 & .129 \\
$\mathrm{~N}$ & 1.000 & 230 \\
SMC average performance & .100 & 1.000 \\
& .129 & 230 \\
\hline $\mathrm{N}$ & 230 & 2 \\
\hline
\end{tabular}

The result (i.e. $\mathrm{r}=0.100$ ) from Table 4 indicates a weaker, positive correlation between rankings for the variables. $(r(230)=.100, \mathrm{p}=.129$ i.e. $\boldsymbol{p}>.05)$. The result implies that there is not much contribution of the sampled SMCs towards the schools' academic performance. Since the significant value was $(p=.129)>.05$, it can be concluded that there is no significant statistical correlation between the two variables. This implies improvements in the performance of SMCs were not very much correlated with school academic performance. Nonetheless, SMCs' performance might be one of the factors associated with school academic performance. This substantiates the findings by Day and Lord, Kaiser, Hagan and Craig (as cited in Wikipedia, free Encyclopedia, 2010) that management contributed to key organizational outcomes. Thus, the inputs SMCs' make in the performance of their assigned roles in school management towards the attainment of quality basic education would eventually affect school academic performance in a very minimal measure.

\subsection{Challenges of SMC}

Research question 3 sought to identify the factors that militate against the SMCs and their activities in schoolscommunities. Table 5 presents the information obtained from the respondents.

Table 5: Distribution of Challenges of SMC

\begin{tabular}{lcc}
\hline Challenges & $\mathrm{N}$ & $\%$ \\
\hline Shortage and transfer of teachers & 15 & 6.5 \\
Lack of funds & 15 & 6.5 \\
Irregular meetings and lack of commitment & 48 & 20.9 \\
Irregular training of members & 41 & 17.8 \\
Absent of motivation for members & 57 & 24.8 \\
Lack of transparency in school finance & 47 & 20.4 \\
Other & 7 & 3.1 \\
\hline Total & $\mathbf{2 3 0}$ & $\mathbf{1 0 0 . 0}$ \\
\hline
\end{tabular}

From Table 5, the major challenges of the SMCs were identified to be absent of motivation for members (24.8\%), irregular meetings and lack of commitment (20.9\%), lack of transparency in school finance $(20.4 \%)$ as well as irregular training of members (17.9\%). The result confirms the opinion of Azeem, (2010) \& AhetoTsegah, (2009) that SMCs are confronted with several challenges leading to poor performance in some communities. 


\section{Summary, Conclusions and Recommendations}

\subsection{Summary of Key Findings}

The study assessed the performance of SMCs in Tarkwa-Nsauem Municipality (TNM). It employed the use of descriptive research design and questionnaires and interview guides as research instruments in data collection. After the quantitative analysis of the data collected, the following findings were made:

i. The SMCs performed majority $(75 \%)$ of their activities. These activities which were also indicators of SMCs' performance were general meetings, school visit, monitoring school attendance and capitation grant, helping teachers' accommodations, ensuring school accountability, settles school disputes, enrolment drive and school retention. However, their performance on critical areas such financial accountability and attendance to executive meetings was very weak.

ii. Contrary to some studies, it was observed that there was a weak positive significant correlation between SMC performance and academic performance in schools.

iii. Some of the factors that militated against the performance of SMCs in the Municipality included but not limited to absent of motivation for members, irregular meetings and lack of commitment, lack of transparency in school finance, as well as irregular training of members leading partly to the inability of SMC members to ensure and insist on school financial accountability.

\subsection{Conclusions}

From the foregoing findings, SMCs' performance in the 10 performance indicators identified above is computed to be $63.6 \%$ which is high indicated that SMCs' had good performance on almost all performance indicators. The study therefore did not support the opinion that school governance vis- a-vis SMC was generally weak and ineffective as observed by Azeem (2010); Etsey et al. (2009). Thus one can conclude that SMC sampled were active and were doing well in their areas of operation. Head teachers thus, need not to face school challenges alone since they may have active and functional SMCs to rely on.

The good performance of the SMCs in the Tarkwa-Nsuaem Municipality is perhaps an indication that SMCs were not becoming a forgotten and dysfunctional phenomenon as depicted by earlier researchers. There was however, a weak positive correlation between SMCs performance and school academic performance. This meant that increases or decreases in SMCs' performance did not significantly relate to increases in school academic performance.

Conclusively, the performance of SMC is therefore one of the major sureties to attaining quality basic education in Tarkwa-Nsuaem Municipality.

\subsection{Recommendations for Policy and Practice}

Based on the findings of the study, the following recommendations were proposed:

i. It was recommended that SMCs should be given the needed support including regular training, especially, on financial accountability. Also much effort is needed to be done by SMCs in the Tarkwa-Nsuaem Municipality (TNM) to ensure quality basic education. Stakeholders should appreciate the sacrifices made by committed members of the SMC. This intervention would increase and retain the zeal of members.

ii. The GES, Government, school authorities and the community should provide the necessary resources to SMCs so that those debilitating factors that have been bottlenecks and impeded the work of SMCs would be minimized. The practice of budget hearing which enables stakeholders to make inputs into school programmes should be encouraged by the school administration as community would make pledges in terms of resource mobilization to execute projects so designed.

iii. To ensure that school drop-outs and absenteeism were brought to the barest minimum, SMCs with the backing of the Unit Committees, Municipal Assembly and the Education Office should enact bye-laws that deal decisively with the issue of school absenteeism. Pupils who go contrary to such laws should be given measured punitive sanctions by the school administration to serve as deterrent to others.

\subsection{Suggestions for Further Research}

Based on the findings of the study, it is proposed that future studies should focus on the role of women in educational decentralization towards the delivery of quality basic education in Tarkwa-Nsuaem Municipality.

\section{References}

Akyeampong, K. (2005). Whole school development in Ghana. http://portal.unesco.org/education/en/files.html Amedahe, F. K., \& Asamoah-Gyimah, K. (2005). Introduction to educational research. Cape Coast: Centre for continuing Education, University of Cape Coast.

Attakpa, S. K., \& Ankomah, Y. A. (1998). Baseline study on the state of school management in Ghana. Journal 
of Educational Management, 1(1), 1-20.

Azeem, A.V. (2010). An overview of the Africa education watch Ghana report. http://www.aew overview.pdf.adobe

Buah-Bassuah, R. (2004). Community participation in junior secondary schools in Twifo Praso Education District. Unpublished master's Thesis, University of Cape Coast, Cape Coast.

Etsey, K., Smith, M. T., Gyamera, E., Koka, J., DeBoer, J., Havi, E. \& Heyneman, S. P. (2009). Basic education in Ghana: Progress and Problems. http://pdf. Usaid.gov/pdf_docs/PNADQ657.pdf

Ghana Education Service (2001). Improving quality education through community participation: PTA/SMC. Handbook. Accra: CSA

Ghana Education Service (2009). Internal budget book: Budget statement \& economic policy of the government of Ghana 1999- 2005. Accra: GES.

Inkoom, A. R. (2003). Teacher management and support services in basic schools in West Akim district of the Eastern Region. Unpublished master's Thesis University of Cape Coast, Cape Coast.

Mensah, K. R. (2003). Community participation in the educational reform: The SMC factor in the ShamaAhanta East Metropolitan. Unpublished Master's Thesis, University of Cape Coast, Cape Coast.

Obeng-Darko, E. (2005). Head teachers and SMC chairmen attend workshop on capitation grant. http://www.ghanaweb.com/ghanahomepage

Opare, J. A. (1999). Academic achievement in private and public schools: Management makes the difference. Journal of Educational Management, 2 (2), 1-12.

Osei-Owusu, B. and Sam, F. K. (2012). Assessing the Role of School Management Committees (SMCs) in Improving Quality Teaching and Learning in Ashanti Mampong Municipal Basic Schools. Journal of Emerging Trends in Educational Research and Policy Studies (JETERAPS), 3(5):611-615.

Owolabi, S. O. (1999). Analysis of trends in Ghana's school-going population. Journal of Educational Management. 2(1), 13-29

Patton, M. Q. (2002). Qualitative evaluation and research methods (3 $3^{\text {rd }}$ ed.). Newbury Park, CA: Sage publications. 